\title{
Image in Clinical Medicine
}

\section{A Large Mass in Lung in a 5-Year-Old Child - Wilm's Tumour with Pulmonary Metastasis}

Received: March 7, 2017 Accepted: April 04, 2017

doi: http://dx.doi.org/10.3329/jemc.v7i2.32659

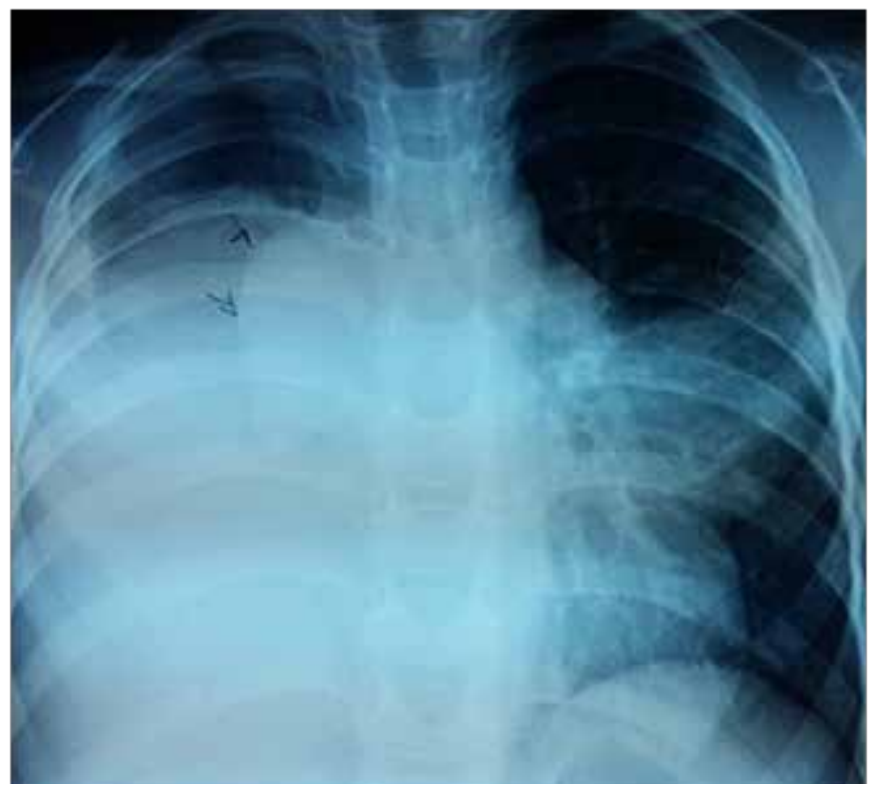

Fig 1. A large homogenous opacity involving middle and lower zone of right lung field and opacity in the mid zone of left lung field
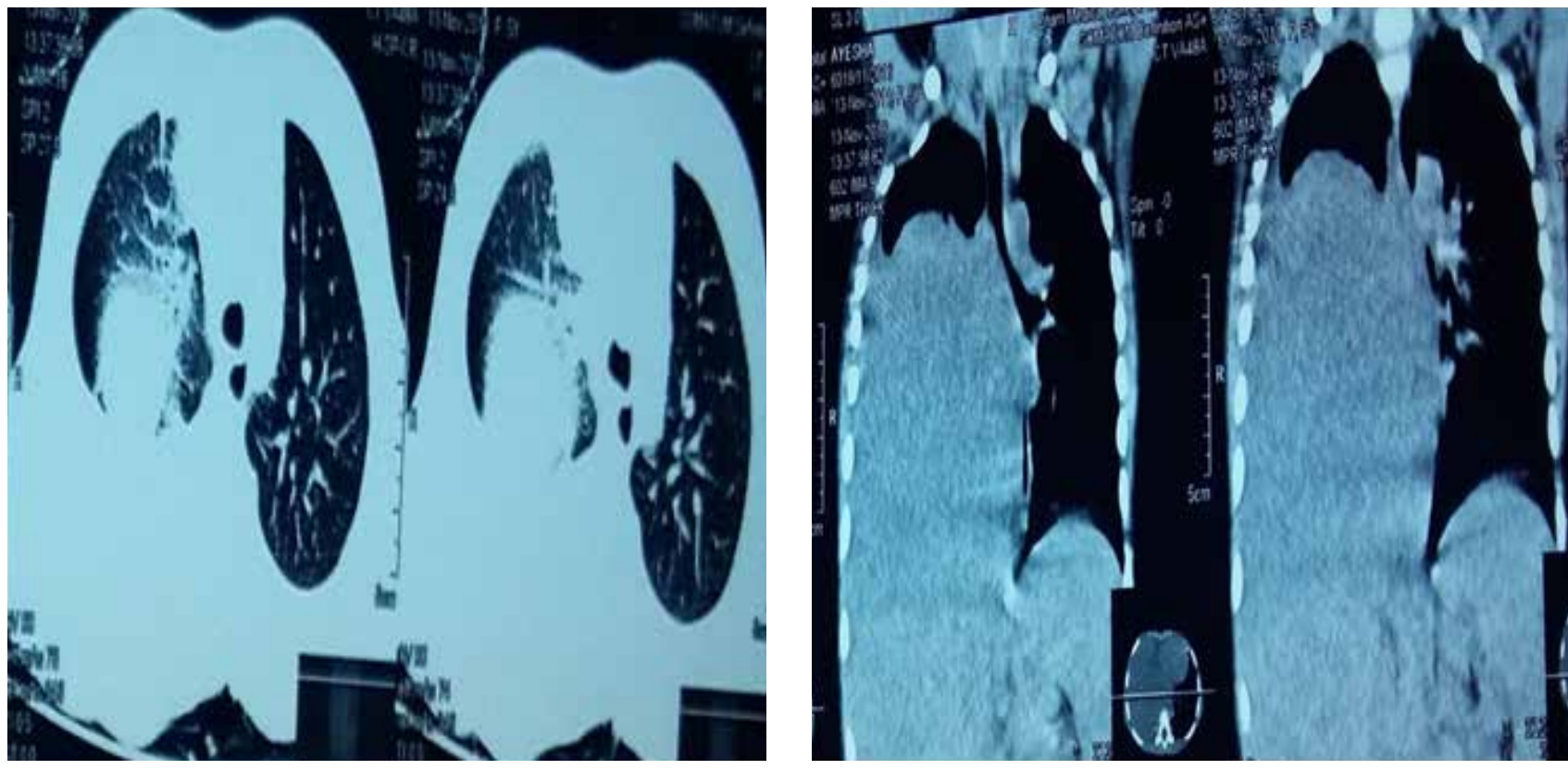

Fig 2. A large soft tissue mass in right chest with bilateral mediastinal lymphadenopathy, marked thick pleural thickening with dense collection/consolidation 
A 5-year-old female baby presented at department of Paediatrics in Enam Medical College Hospital with the complaints of fever for two months and cough for 14 days. Cough was productive but not associated with blood. She underwent right sided nephrectomy one year ago due to Wilm's tumour. On the day of admission patient developed respiratory distress. On examination, there was chest indrawing, respiratory rate was 46 breaths/minute, pulse 90 beats $/ \mathrm{min}$ and temperature was $100^{\circ} \mathrm{F}$. On auscultation breath sound was found diminished on right lung field. Investigation revealed neutrophilic leukocytosis and high $\mathrm{LDH}$ level. Chest radiography showed a large homogenous opacity involving middle and lower zones of right lung field and opacity in the mid zone of left lung field. High resolution CT scan (HRCT) of chest showed a large soft tissue mass in right chest with bilateral mediastinal lymphadenopathy, marked thick pleural thickening with dense consolidation and it was diagnosed as a metastatic mass or lymphoma. She was treated with intravenous antibiotic cefuroxime, vancomycin and clarithromycin for seven days. Her clinical condition improved slightly. She was discharged and referred to the department of Paediatric Haemato-oncolgy for further evaluation and treatment.

Wilm's tumour, also known as nephroblastoma, is the most common primary malignant renal tumour and second most common abdominal tumour of childhood. It accounts for $6 \%$ of all childhood malignancy. ${ }^{1}$ The most common presentation includes abdominal mass, hypertension, fever and gross painless haematuria. The sites of metastases include lung, regional lymph node and liver with lung being the most common site. ${ }^{2}$

Metastatic lung disease in the patients with Wilm's tumour is traditionally identified by chest radiography, but chest $\mathrm{CT}$ is the most sensitive tool to screen pulmonary metastasis. ${ }^{3}$
According to the International Society of Paediatrics Oncology (SIOP), treatment strategy consists of multiple agents chemotherapy, surgery and sometimes radiotherapy. ${ }^{4}$ In pulmonary metastasis disease free survival may vary from two to three years after initial treatment. $^{5}$

\section{Dr Lazina Sharmin}

Assistant Professor

Department of Paediatrics

Enam Medical College \& Hospital, Savar, Dhaka

Email: drlazina22@yahoo.com

\section{References}

1. Daw NC, Huff V, Anderson PM. Neoplasm of kidney. In: Nelson textbook of Paediatrics. $20^{\text {th }}$ edn. India: Elsevier, 2015: 2462-2466.

2. Macklis RM, Stephen BA, Sallan E. Wilm's tumour patients with pulmonary metastases. International Journal of Radiation Oncology Biology Physics 1991; 21(5): 1187-1193.

3. Grunndy PE, Green DM, Dirks AC, Berendt AE, Breslow NW,Anderson JR et al. Clinical significance of pulmonary nodules detected by $\mathrm{CT}$ and not CXR in patient treated for favourable histology Wilm's tumour on national Wilm's tumour studies 4 and 5: a report from children oncology group. Padiatr Blood Cancer 2012; 59(4): 631-635.

4. Verschuur A, Van Tintern H, Graft N, Bergeron C, Sandstedf B, Kraker J. Treatment of pulmonary metastases in children with stage 4 nephroblastoma with risk based use of pulmonary radiotherapy. J Clin Onco 2012; 30(28): 353-359.

5. Bond JV, Martin EC. Pulmonary metastases in Wilm's tumour. Clin Radiol 1997; 27(2): 191-195. 